\title{
Archaeology and Research in the History of Kashmir- Perspectives and Concerns
}

\author{
Abdul Adil Paray \\ Research Scholar, AIHC and Archaeology, Indira Gandhi National Tribal University, Amarkantak, Madhya Pradesh, India \\ Corresponding author: aadil.hist15@gmail.com (ORCID ID: 0000-0002-1827-4347)
}

Received: 23-10-2020

Revised: $11-01-2021$

Accepted: 28-02-2021

\begin{abstract}
Research in history is digging into the past through multidisciplinary approach, with the requisites of professionalism, critical aptitude, technical erudition, analytical mind and incisive faculty to reconstruct the past and to elaborate, analyze, synthesize, philosophize the ideas and critically examine the data in the light of objectivity. Historical research is primarily based on literary and archaeological sources. Literary sources are more or less infected of personal bias and prejudice by the author or interpreter. So, here archaeology comes to rescue for reconstructing comparatively an unbiased history. Archaeology is an auxiliary science or ancillary discipline with its numerous approaches, which assist in historical research. It is a sub-discipline of anthropology which is concerned with the study of human evolution and his environment and the material culture associated with him in pre-historic, proto-historic and historic periods through practical undertakings, methods and theories. Kashmir is an ancient geological land with glorious past where the man lived since the pre-historic times and has always been contacts with her neighbors and witnessed influx and efflux of races and cultures. So the role of archaeology with literature is of vital significance in the research of history of Kashmir. But, the application of archaeology in the research of history of Kashmir in general and in ancient and medieval history in particular seems very negligible. The attitude and interest of research about the ancient history of Kashmir and fresh explorations of archaeological sites among the regional institutions,students and scholars is meager. The national and international surveys and studies about archaeological research have also come to halt. The deteriorating condition of archaeological sites in the valley gives us the glimpse of our vanishing history. Archaeology is not confined to historical archaeology, it includes ethno-archaeology, Environmental Archaeology, Rural and Urban Archaeology, Marine Archaeology, and the list goes on. In this paper I will try to investigate the different perspectives and concerns of archaeological research in the history of Kashmir, its application on vast and wide areas of research, keeping in view the post-processual and postmodern viewpoint. Besides methodological problems, descriptions and fundamental goals, this paper seeks to evaluate the reasons why and based on these evaluations some suggestions for future research in Kashmir history are proposed. As the history of Kashmir is the significant and an inseparable part of Kashmir Studies.
\end{abstract}

\section{Highlights}

(0 This paper highlights the problem of research attitude of the research institutes and research scholars of Kashmir towards Prehistory in particular and ancient history in general. Kashmir history has been written and analyzed from literary sources and archaeological sources are rarely employed.

(0 The prehistoric research area is almost neglected and material culture as a source of History writing is considered a hard task in research data collection.

(0 This paper attempts to focus over significance of archaeological sources in construction of historical narratives.

How to cite this article: Paray, A.A. (2021). Archaeology and Research in the History of Kashmir- Perspectives and Concerns. Int. J. Soc. Sci., 10(01): 63-67.

Keywords: Archaeology, Kashmir History, Research, Sources, Methodology 
There is a close relationship between the literary texts and archaeology. Following Fernand Braudel and the Annales School, we can distinguish three levels or tiers of history. The deepest level of history can be referred to as "geographical time." It addresses the relationship of humans to their environment. This is history in which all change is slow and undergoes a constant repetition. At this level, we can discuss ecology and human subsistence. We might discuss long-range settlement patterns. This level of history presents the common fate of humans beyond the influence of conscious decisionmaking. In regard to the history of ancient Kashmir, this level addresses the Kashmiri settlement in the context of the oscillating periods of settlement of the ancient period. Archaeology provides the primary evidence for this level of history. The second, intermediate level of history can be referred to as "social time." This level addresses the social relationships among human groups. This is the level of cultural changes,and thus is a history with slow but perceptible rhythms. In regard to the history of ancient Kashmir, this level can address the influx of various central Asian races and ethnic groups since Neolithic period. Archaeology and provide evidence for understanding history at this level. The final, surface level of history can be referred to as "individual time." This level addresses the rapidly changing history of human events. This is the level of political history;it is at this level that history becomes narrative. In terms of our evidence, the textual record is best suited for addressing historical questions at the surface level of individual time. Archaeology can also contribute to this level of history, but generally only in supplying the material context for the events. Moreover, archaeology transcends the limitations of written records and can reveal detailed stories when no document exists.

In archaeology, archaeologists use time, space and information gleaned from artifacts, sites and their contexts to construct the history. It does not mean, archaeology is unique in shedding light on past human events; history has been giving us volumes of detailed records spanning centuries. Instead the essence, the necessity, of archaeology lies in its ability to reveal the entire human record. Accordingly, archaeologists include both the recent and the distant past in their investigations as contrary to public perception, archaeological research is not limited to the study of pre-literate societies or prehistory. Also historical archaeology is not limited to stone tools and like but its scope envisages the total history. Besides social, economic and cultural archaeology, Historical archaeology encompass anthropology, demographic archaeology, environmental archaeology, ecological archaeology, epistemology, ethnoarchaeology, feminist archaeology, gender archaeology, landscape archaeology, urban and rural settlement archaeology, post-processsual and interpretive archaeology, cognitive archaeology, marine archaeology etc.

\section{Archaeology and Research in History of Kashmir}

Although archaeology and history are today independent disciplines, any work in the archaeology of Kashmir eventually have to address issues stemming from historical texts of the region. Students of the history in general and Kashmir history in particular need to beware of a common naive assumption regarding the relationship between history and archaeology: Archaeology serves to complement history and to support or falsify the historical record. This assumption is an expression of the commonly held priority that is given to literary texts for history of Kashmir. Literary evidence often sets the agenda for the research of non-literary material culture. The corollary to this assumption is that non-literary material culture is mute, cannot speak, without an appropriate context supplied by literary evidence. Unfortunately, this assumption expresses a naivete about the role of material culture (symbolic expressions) for constructing meaning about the past. Indeed, it is because of the inherent deficiencies of historical texts for understanding the society, economy, and religion of an ancient people that archaeology provides such a valuable resource. But the material remains of archaeology are not subordinate to the textual record for historical study. Like texts themselves, material remains are symbolic expressions encoding messages about the past. They similarly require a critical interpretation before they can be used in understanding the past. Material remains are thus not mute; rather, the historian must learn to "hear" what they "speak" about 
the past in dialogue with the questions posed to them. For example, floral and faunal remains "tell" about the economy of a people, about their vocations, about their diet; architectural structures "give witness" to the social and gender stratification of society and to the kinship structures and relations within a village or a habitat; cultic artifacts "speak" about the theology and religious practices of an individual, a family, or a community. Since archaeology has wide boundaries to include not only Prehistory but the different multi-dimensional cultures. Archaeology provides comparatively a different kind of evidence than literary texts, such as the Nilmatpurana, Rajatarangini or medieval Persian texts etc. In contrast to these texts that have undergone several generations of revision through different translations in varied contexts, and to other literary texts whose content has been selectively chosen by an author, archaeological evidence is analogous to primary sources. It is frozen in time, attesting to the ancient or medieval world firsthand. Archaeological evidence has not been subject to the secondary reformulation that is characteristic of the literary process. Archaeological remains are random and unintentional. They constitute, therefore, an external witness to the past. In this way, archaeological evidence is more "objective." The paper is an introduction to research techniques or methods used by historians of Kashmir for reconstructing the histories of pre-literate societies, including those groups embedded within larger literate ones by employing the archaeological data besides interpreting the literary sources.

Archaeology is for and about people but beyond that, the science of archaeology is comprised of both theory and method and in the research of historical themes both are prerequisites. Research in history of Kashmir is mostly accumulation of facts and data or even a portrayal of past events. It is a flowing, vibrant report of past events which involves an analysis and explanation of these occurrences with the objective of recapturing the nuances, personalities and ideas that influenced these events and keeping the other things constant which seems irrelevant to the research context. Conducting historical research about Kashmir history involves the process of collecting and reading the research material collected and writing the manuscript from the data collected. The researcher often goes back-and-forth between collecting, reading, and writing i.e., the process of data collection and analysis are done simultaneously are not two distinct phases of research. The research about Kashmir history is analytical in that it uses logical induction and has a variety of foci such as issues, events, movements and concepts. But, the multidisciplinary nature of modern archaeology can make research in Kashmir history more objective, valid and authentic by taking help from biology, chemistry, physics, geology, mineralogy, paleontology, philology, paleoclimatology, paleo-botany, archaeozoology, remote sensing, GIS, GPS, cartography, etc. and absolute dating techniques can help in constructing a chronologically more accurate history. In other words the concept of historical archaeology should be used as an effective tool in the research of Kashmir history. As Historical archaeology is the outcome of the rich play between word and object, text and artefact.

Most of the written history of Kashmir tells us only about the particular events, "high status" individuals and elite happenings and even then, there are many aspects of the lives of notables and events for which we lack information. And there are many aspects of day to day life which were considered mundane or routine that they were not recorded, many individual events which together form a compelling social pattern have likewise gone unrecorded. By investigating this patterning, archaeology serves to modify an otherwise biased view of the past by placing the present in a more accurate historic context. It allows us to discover cultural patterning not otherwise recoverable. The lives of most women, children, peoplein lower socio-economic classes, ethnic and racial minorities and people living in more geographically isolated locations are conspicuously underrepresented in the written records. The emerging emphasis on social archaeology has attempted to correct the imbalance and possesses the ability to find answers to important questions. Archaeological investigation of associated physical remains is extremely important, since archaeology is the only available means to identify and "read" these sites and their histories.

Kashmir has been the abode of man since Paleolithic times, followed by Neolithians, Harappans, Mauriyas, 
Shakas, Kushanas, Hunas, Karkotas, Utupalas, Loharas, Sayids, Chaks, Mughals, Afghans, Sikhs and Dogras. So the archaeology can provide the specific material context for many of the events narrated in literary texts, much of which the narratives themselves do not address. There are hundreds of prehistoric and historic sites in Kashmir which are in shambles. We have a fertile field for scientific historical research with both material remains and the texts. What we require is a broad understanding of method, theory, and historic preservation, use of archaeological and literary sources for a good research. What I mean to say is that research in Kashmir history employs literary sources and material remains that have been excavated decades ago. There are negligible attempts to recover more archaeological data. We need to use archaeology as a tool to take full advantage of the information that material remains embody. Archaeology touches on the entire spectrum of human behaviour and so inspires a never ending series of questions to reconstruct history of Kashmir from different frames of reference and diverse cultures. The multidimensionality of the discipline of archaeology has great significance and implications for both resource management and research decisions. The archaeological material has historical significance, research and scientific significance, ethnic significance, geographic significance, public significance etc. In these contexts the use of archaeology in the research of history can yield fruitful and objective annals of Kashmir history.

\section{CONCLUSION}

Archaeology has long been accepted as a scientific discipline providing tangible evidences with intangible context for building up the superstructure of history. In fact, its claim is accepted as supreme especially in such periods where written records are absent or have remained undeciphered. Where, however, written records exist, the archaeological material remains turned up by the spade convey in a telling manner the import of the written word. Archaeological material of all historical time periods must be used in historical research warranted by written facts, aids in complete objectivity and serves the very purpose of scientific enquiry into history. The valley of Kashmir has a rich and diverse history including prehistory, ancient, medieval and modern history with expanding and varied historical processes. Unintentional and formal explorations, surface and chance findings substantiate the validity and role of archaeology for scientific research in the history of Kashmir. Archaeological remains illuminate the daily life of the peoples living in the past and even in present, which supplements the literary texts. Only from archaeology can we learn about the planning of the Kashmiri villages, towns and cities; the architecture of palaces, houses,temples, Mosques and public buildings; figurines, altars, and other cult objects; tombs and the different peoples' treatment of their dead; luxury items such as jewellery, carved stones and wooden objects, metal and stone vessels, arts and crafts, imported items; and common tools and weapons. Archaeology enables us to reconstruct every aspects of the society, economy, and religion of the ancient, medieval and modern peoples that are sometimes neglected by the textual tradition. Furthermore, because archaeological evidence is random -its preservation is by chance, unaffected by human selection - it provides an alternative perspective from which to view the literary narratives.

\section{REFERENCES}

Deshpande, M.N. 1968. Archaeological Sources for the Reconstruction of the History of Sciences of India. His. Sci. India, 6(1), New Delhi.

Fimbel, Deborah, 1996. Archaeology and the Importance of Shifting for Answers about our Forgotten Past, Historic Preservation Planning Bulletin, New Jersey.

Renfrew, Colin., Bahn, Paul. 2005. Archaeology- The Key Concepts, Routledge-Taylor \& Francis Group, London.

Smith, Charlotte A. and Harris, Jannifer Freer. 2000. Why is Archaeology Important?, Early Georgia, Vol. 29.

Shali, S.L. 1999. Kashmir: History and Archaeology Through the Ages, Indus Publishing Company, New Delhi.

Bandey, Aijaz A. 2009. Prehistoric Kashmir-Archaeological History of Palaeolithic and Neolithic Cultures, Dilpreet Publishing House, New Delhi.

Koul, Panduit Anand, 2005. Archaeological Remains in Kashmir, Gulshan Books, Srinagar.

Kak, R.C. 2002. Ancient Monuments of Kashmir, Motilal Banarsidas, New Delhi. 
White, Nancy, 2000. Introduction to Archaeology, Mayfield Publishing Co., California.

Berlin, Isaiah. 1960. The Concept of Scientific History, Blackwell Publishing, USA.
Fienman, Gary M. 2015. Settlement and Landscape Archaeology, Elsevier Ltd., Chicago. 
